\title{
A Transformational and an Authentic Leader Walk into a Bar: Who Feels Included?
}

\author{
Katrina P. Merlini \\ Florida Institute of Technology \\ Ché Albowicz \\ McChrystal Group \\ Paul G. Merlini \\ Human Resources Technologies Inc.
}

\begin{abstract}
Drawing from social information processing theory and social learning theory as theoretical bases, this study examined whether transformational and authentic leadership styles predict perceptions of inclusive environments and whether the styles differ in the relative importance of their prediction. Using multilevel modeling techniques, results demonstrated that both styles independently predict perceptions of inclusive environments. Fit indices were slightly better for the transformational leadership model. Dominance analysis revealed transformational leadership had slightly greater importance in predicting perceptions of inclusive environments. Results suggest both styles are important in predicting perceptions of inclusive environments.
\end{abstract}

Keywords: Transformational leadership, Authentic leadership, Inclusion, Inclusive, Dominance analysis.

\section{INTRODUCTION}

Inclusion is when "people of all identities and many styles can be fully themselves while also contributing to the larger collective, as valued and full members" (Ferdman, 2014, p. 235). Consistent with Shore et al.'s (2011) conceptual work on the subject, this definition highlights two important components of inclusion: both cohesiveness and a value for individual uniqueness. In the past several years, inclusion has been recognized as a critical factor in maximizing the benefits of diversity and retaining diverse workers (e.g., Ferdman, 2014; Shore et al., 2011). However, inclusion-related research is still in early stages and more research is needed on this important construct (Shore, Cleveland, \& Sanchez, 2018), including what factors may influence inclusive organizational environments. Recently, there have been arguments put forth regarding ways in which leadership styles may impact perceptions of inclusion and inclusive environments (e.g., Brimhall et al., 2017; Gotsis \& Grimani, 2016; Randel et al., 2018). Previous research suggests leaders play a large role in shaping perceptions of workplace 
environments (e.g., Liao \& Chuang, 2007); yet, leadership styles have been somewhat understudied in the inclusive environment literature.

Authentic leadership (AL) and transformational leadership (TFL) are both widely studied styles (Banks, McCauley, Gardner, \& Guler, 2016; Mhatre \& Riggio, 2014) that may be particularly important in impacting perceptions of inclusive environments. Previous research offers initial support for AL and TFL predicting perceptions of inclusive environments; however, much of this work has been conceptual (Boekhorst, 2015; Gotis \& Grimani, 2016) or has utilized less recent or less complete conceptualizations of key constructs (e.g., Ashikali \& Groeneveld, 2015; Cottrill, Lopez, \& Hoffman, 2014). Further, previous research has suggested that, although AL and TFL are highly related constructs, they may differ in their prediction of certain types of outcomes (Banks et al., 2016) and more research is needed to examine these differences. Therefore, the purpose of this research is to explore whether these leadership styles predict perceptions of inclusive environments and, if so, how they may differ in their prediction. To do so, we draw from social information processing theory (SIP, Salancik \& Pfeffer, 1978) and social learning theory (SLT, Bandura, 1977) to explain how these leadership styles should foster perceptions of inclusive environments, as conceptualized by Nishii (2013), and test proposed relationships using a multilevel model (MLM) approach. Further, we examine model fit indices and dominance analysis results to compare these leadership styles in their prediction of inclusive environment perceptions.

\section{Inclusive Environments}

Perceived workplace environments, or climates, may be defined as "experientially based description of what people see and report happening to them in an organizational situation" (Ostroff, Kinicki, \& Tamkins, 2003, p. 566). Over the years, the study of workplace environments has become more specific and focused on either tangible outcomes (e.g., safety) or processes that are expected to aid in organizational outcomes (Schneider, Ehrnhart, \& Macey, 2013). Relatively recently, Nishii (2013) expanded both the inclusion and climate literature by defining and examining inclusive environments as a process by which organizations can enhance diversity-related outcomes.

Individuals are expected to perceive their environments as inclusive when "individuals of all backgrounds - not just members of historically powerful identity groups - are fairly treated, valued for who they are, and included in core decision making" (Nishii, 2013, p. 1754). These types of environments involve three dimensions. First, fairly implemented employment practices involve unbiased employment practices and diversity practices that reduce or eliminate discrimination. Second, integration of differences involves the extent to which employees accept other employees for acting in accordance with their core selves without consequence. Finally, inclusion in decision-making is the extent to which diverse employee perspectives are solicited and incorporated, even when they are contrary to the norm. This conceptualization of inclusive environments has been shown to result in various positive outcomes, such as the reduction of conflict, burnout, and turnover intentions (Merlini, Bupp, Merlini, \& Garza, 2018; Nishii, 2013)

\section{Leadership and Inclusive Environments}

Leadership has been shown to impact individuals' perceptions of workplace environments (for a review, see Schneider et al., 2013). SIP and SLT are theoretical bases that explain how this may occur. According to SIP, employees draw cues from their social environments that they then use to make sense of their workplace environments (Salancik \& Pfeffer, 1978). Leaders are a likely source of these cues and may provide them directly, such as by stating the organization's values, or indirectly, such as through their everyday interactions with followers (Thomas \& Griffin, 1989). Further, in accordance with SLT (Bandura, 1977), followers may model their behaviors after leaders and vicariously learn what behaviors are appropriate through watching leaders' interactions with others. Taken together, if these cues and learned behaviors support inclusion, perceptions of inclusive environments should ensue. We argue that $\mathrm{AL}$ and TFL may provide cues and learned behaviors that support inclusive environments. 


\section{AL and Inclusive Environments}

AL refers to a values-based style of leadership in which leaders behave in accordance with their true selves (Leroy, Anseel, Gardner, \& Sels, 2015) and is characterized by four dimensions: self-awareness, relational transparency, balanced processing, and internalized moral perspective (Gardner, Cogliser, Davis, \& Dickens, 2011). AL is described as a central theme for organizations that value uniqueness (Shore et al., 2018) and is associated with various positive follower outcomes (for a review, see Gardner et al., 2011), as well as group-level outcomes (Walumbwa, Luthans, Avey, \& Oke, 2011; Hannah, Walumbwa, \& Fry, 2011). Cottrill and colleagues (2014) found initial evidence that AL predicted inclusion; however, the authors utilized Walumbwa and colleagues' (2008) measure of AL. Banks and colleagues (2016) indicate that this measure may need refinement and suggest continued application of Neider and Schriesheim's (2011) measure. Further, Cottrill and colleagues (2014) utilized Mor Barak and Cherin's (1998) measure of inclusion-exclusion, which is substantively different from Nishii's (2013) inclusive environment conceptualization. For instance, Mor Barak and Cherin's (1998) scale focuses on perceptions of whether an employee feels included vs. excluded as opposed to the inclusiveness of the larger workplace environment. Additionally, Mor Barak and Cherin's (1998) conceptualization does not include dimensions key for representing the value for uniqueness component of inclusion, which is present in Nishii's (2013) integration of differences dimension. Therefore, we build on this previous work by examining the relationship between $\mathrm{AL}$ and inclusive environments using more recent conceptualizations and measures of the constructs.

Self-awareness encompasses a deep understanding of strengths, weaknesses, values, and preferences (Walumbwa, Avolio, Gardner, Wernsing, \& Peterson, 2008). Authentic leaders use this self-knowledge to drive their relations with others (Avolio \& Gardner, 2005). Through self-awareness, authentic leaders act in accordance with their true selves and show comfort with being their authentic selves (Luthans \& Avolio, 2003). Followers may model similar behaviors related to authentic displays of self via SLT. Further, in accordance with SIP, followers may perceive authenticity is valued when leaders display interest in understanding their own strengths and weaknesses. Together, these processes may support both the integration of differences and the basic tenant of inclusion that employees need to be authentically themselves (Shore et al., 2018), thus, promoting perceptions of inclusive environments.

Relational transparency refers to behaving openly and transparently with others (Walumbwa et al., 2008). AL theory suggests this transparency evokes followers' trust (Gardner et al., 2011), builds open lines of communication, and encourages information sharing (Avolio, Gardner, Walumbwa, Luthans, \& May, 2004). By engaging in these behaviors, leaders may inform followers that transparency and information sharing are valued and, via SLT, followers may model leader's open communication style and feel comfortable sharing their unique perspectives. Thus, relational transparency may support the integration of differences component of inclusive environments. Ilies, Morgeson, and Nahrgang (2005) suggest AL induces personal identification with the leader, who represents the values of the group, resulting in followers' social identification with the group. Thus, authentic leaders may exert an indirect effect on social identification and inclusivity through personal identification with authentic leaders.

Balanced processing refers to an objective analysis of all relevant information, including information that is in opposition to one's currently held beliefs, before coming to a decision (Walumbwa et al., 2008). By analyzing diverse perspectives before making decisions, AL supports inclusion in decision-making. To obtain all relevant information when making decisions, authentic leaders will seek and consider diverse perspectives (Walumbwa et al., 2008), thus modeling behaviors and sending cues related to the importance of shared decision-making and diversity of thought (supporting integration of differences), which underlie inclusive environments.

Internalized moral perspective refers to leaders' commitment to behaving consistently with core ethical values and internal standards (Gardner et al., 2011). Authentic leaders inform followers of the value placed on inclusion through modeling ethical behavior and placing emphasis on fairness in processes. This dedication to ethical standards and fair treatment should support Nishii's (2013) fairly implemented employment practices component of inclusive environments. 
Hypothesis 1: AL will positively relate to perceptions of inclusive environments.

\section{TFL and Inclusive Environments}

TFL generally concerns inspiring and developing followers to reach their highest potential and is typically characterized by four dimensions: idealized influence, intellectual stimulation, individualized consideration, and inspirational motivation (Bass \& Avolio, 1990). TFL has been widely researched and has been demonstrated to impact a variety of important outcomes (Banks et al., 2016; Judge \& Piccolo, 2004). To date, however, only one study has examined the TFL-inclusive environment relationship. This study, by Ashikali and Groeneveld (2015), described TFL's role in reducing the negative impact of diversity (rather than fostering inclusion) and operationalized inclusion in ways that differ substantively from Nishii's (2013) conceptualization (i.e., inclusion in decision-making is absent). Therefore, we expand upon this study by explaining how dimensions of TFL may foster inclusive environments, as conceptualized by Nishii (2013).

First, idealized influence involves leaders who display authenticity and act in accordance with high performance and ethical standards (Sosik \& Jung, 2010). These behaviors are expected to foster followers' commitment to the leader and inspire them to want to emulate the leader (Bass, Avolio, Jung, $\&$ Berson, 2003). Idealized influence provides the foundation for why followers would view a leader as a role model, which, drawing from SLT, may result in followers modeling leader behaviors such as those that support inclusion, further fostering inclusive environments. Additionally, the ethical component of this dimension may manifest in leaders' equitable treatment of diverse members and upholding policies related to fairness in the workplace, which may foster the fairly implemented employment practices dimension of inclusive environments.

Intellectual stimulation involves leaders supporting creativity and innovation in followers (Bass et al., 2003). Part of this dimension involves leaders seeking diverse perspectives (Sosik \& Jung, 2010), which should model behaviors related to Nishii's (2013) description of inclusion in decision-making. By engaging in this behavior, a leader may send cues that different perspectives are valued, supporting Nishii's integration of differences dimension. This dimension involves encouraging followers to reexamine their assumptions and think in unconventional ways (Bass et al., 2003). This may also facilitate integration of differences, as individuals may be more likely to question majority norms and stereotypes; thus supporting environments more accepting of diverse members and viewpoints.

Individualized consideration includes "dealing with others as individuals and considering their needs, abilities, and aspirations" to help them develop (Sosik \& Jung, 2010, p. 195). Making efforts to get to know followers as individuals and treating them as such may also foster the integration of differences in the workplace. In doing this, leaders may be sending cues that unique identities are valued. Modeling these behaviors may also results in others getting to know the unique identities of fellow workgroup members, ultimately supporting workplace environments that value individual differences.

Finally, inspirational motivation includes "leader behavior that involves developing and articulating a vision" that engages and energizes followers (Sosik \& Jung, 2010, p. 16). This dimension may not directly relate to the components of inclusive environments; however, if inclusion is important to leaders' goals, this dimension could involve articulating inclusion as part of the vision. If this is the case, leaders who are adept at inspirational motivation may be more likely to have followers' "buy-in" for the importance of inclusion and motivate them to be more inclusive. Taken together, there is reason to believe that dimensions of TFL may foster perceptions of inclusive environments.

Hypothesis 2: TFL will positively relate to perceptions of inclusive environments.

\section{AL, TFL, and Inclusive Environments}

Based on the above arguments, it is likely that both AL and TFL predict perceptions of inclusive environments. However, it is unclear whether differences in their predictive capabilities exist. Banks and colleagues (2016) speculate that AL may have a stronger relationship with outcomes that support 
collective interests, which may include perceptions of inclusive environments. However, it is unclear whether this speculation is accurate in this situation.

Research Question: How do AL and TFL compare in their prediction of perceptions of inclusive environments?

\section{METHOD}

\section{Participants and Procedure}

Data for this study came from the Defense Equal Opportunity Management Institute (DEOMI) Climate Survey (DEOCS) 4.1 collected in July 2018. The DEOCS assesses the perceptions of individuals in the Department of Defense (DoD) on core areas such as equal opportunity and organizational effectiveness. Additional modules are included to collect data for research. Leadership measures were included in these modules for a 4-week period. A total of 15,797 participants from 1,366 units responded. A random subsample was selected from the data to utilize in the current study. The subsample includes 3,834 participants from 966 units. The majority of the subsample was male (76\%) and Caucasian (60\%). Complete demographics can be viewed in Table 1 (see Appendix).

\section{Measures}

Authentic Leadership

AL was measured using Neider and Schriesheim's (2011) 14-item Authentic Leadership Inventory ( $\alpha$ $=$.97). Participants were asked to indicate their level of agreement for each statement in regard to their senior leader (defined to participants as their current unit commander or civilian equivalent) and items were rated on a five-point scale $(1=$ Strongly disagree, $5=$ Strongly agree $)$. Items were modified slightly to fit the DoD context (e.g., "senior leader" as the subject). Example items include, "My senior leader uses his/her core beliefs to make decisions" and "My senior leader encourages others to voice opposing points of view."

\section{Transformational Leadership}

TFL was measured with 15 items from Xirasagar, Samuels, and Stoskopf's (2005) adapted version of the Multifactor Leadership Questionnaire $(\alpha=.97)$. Individuals were asked how frequently each statement fit their senior leader and items were measured on a five-point scale $(1=$ Not at all; $5=$ Frequently, if not always). There were three items in the inspirational motivation and individualized consideration dimensions and four items the idealized influence and intellectual stimulation dimensions. Items were modified slightly to be in active voice ("Communicates" vs. "Communicating"). Example items include, "Seeks differing perspectives on problems" and "Recognizes that individuals have different needs, abilities, and aspirations."

\section{Perceptions of Inclusive Environments}

Perceptions of inclusive environments were measured with six items $(\alpha=.89)$. These six items were modeled after Nishii's (2013) inclusion climate measure and modified to be appropriate for a DoD population. Each facet of inclusion was represented by two items and items were rated on a seven-point agreement scale $(1=$ Strongly disagree; $7=$ Strongly agree $)$. Example items include, "Coworkers are treated as valued members of the team without losing their unique identities" and "Within my workgroup, I am encouraged to offer ideas on how to improve operations."

\section{Control Variables}

Demographic characteristics of gender $(1=$ male and $2=$ female $)$, minority status $(1=$ minority, $2=$ majority [i.e., White, Non-Hispanic], 3 = declined to respond), and rank (coded 1-9 to represent various categories of military and civilian rank identified in Table 1) were included as control variables. 


\section{RESULTS}

\section{Preliminary Analyses and Analytical Approach}

Bivariate correlations were conducted among discrete and continuous variables (see Table 2) using IBM SPSS $^{\circledR}$ software. Consistent with previous research (Banks et al., 2016; Rodriguez, Green, Sun, \& Baggerly-Hinojosa, 2017), results revealed high correlations between leadership styles, suggesting some redundancy in the measures.

Due to the non-independent nature of the data where individuals were nested in units (allowing for the possibility of sharing senior leaders), multilevel analytical approaches were used to test hypotheses. Although data may be aggregated to the unit level to examine shared perceptions of leader behavior on shared perceptions of inclusive environments (e.g., climate level aggregation, see Schneider et al., 2013), unit size and, thus, response rate data was not available making extrapolations to the unit-level potentially inappropriate. Further, we suspect that there may be meaningful individual-level differences that exist among perceptions of leader behaviors and inclusion perceptions. For instance, while one unit member may perceive the leader's behavior in one way, it may be possible for another unit member to perceive the same leader's behavior differently, due to factors such as schemas and cognitive biases, that affect what information is attended and how it is interpreted (e.g., Taylor, 1989). RStudio was used for these multilevel analyses.

TABLE 2

\section{DESCRIPTIVES AND CORRELATIONS OF STUDY VARIABLES}

\begin{tabular}{lcccc}
\hline Variables & Mean & $S D$ & & \\
\hline Inclusion & 5.01 & 1.39 & - & \\
$\mathrm{AL}$ & 3.66 & 0.91 & $.68^{*}$ & - \\
$\mathrm{TFL}$ & 3.71 & 1.02 & $.68^{*}$ & $.84^{*}$ \\
\hline Note: ${ }^{*}=p<.01$. & & & &
\end{tabular}

\section{Hypothesis Testing}

Before testing the hypotheses and research question, an unconditional means model with individuals nested in units and inclusion as the dependent variable was examined (Model 1). Results revealed variance in inclusion at both Level-1 and Level-2 (see Table 3 for MLM results). Next, control variables were entered at the individual level (Level-1), forming Model 2. Results revealed variance in the model remained; therefore, predictors were added to the model to test the hypotheses. Both AL and TFL were group-mean-centered prior to running the analyses (Peugh, 2010). First, Model 3 was formed by adding AL to Model 2 as a Level-1 predictor. Results indicated there was a significant positive relationship between inclusion and AL $(\gamma=1.00, p<.001)$; supporting Hypothesis 1 . AL was then removed and TFL was added as a Level-1 predictor, forming Model 4. Results revealed there was a significant positive relationship between inclusion and TFL $(\gamma=0.92, p<.001)$; supporting Hypothesis 2. Table 3 displays additional results of the MLM models. 


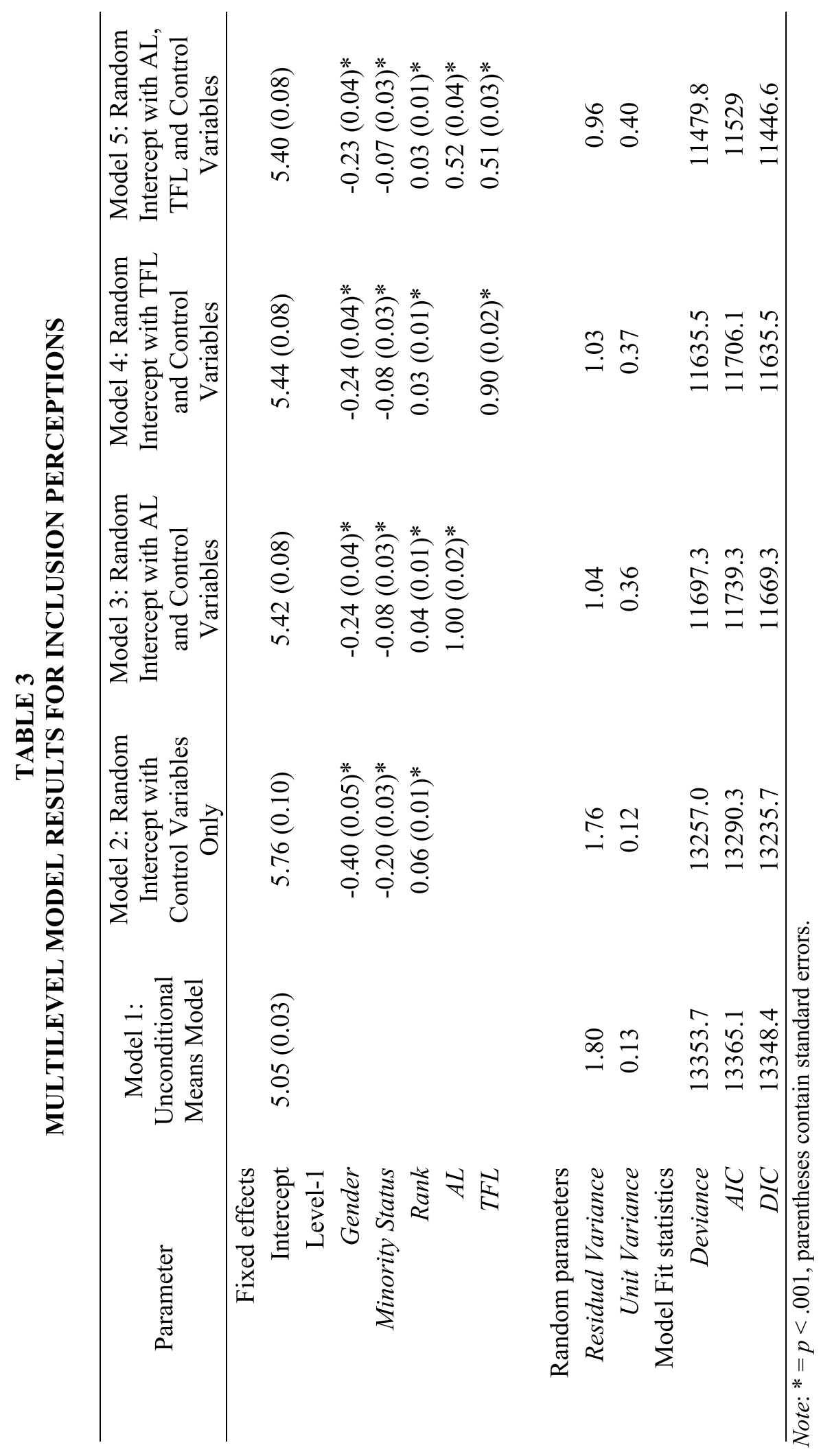




\section{Comparison of Leadership Styles}

Leadership styles were compared two ways. First, model fit was compared between the two models using the Akaike Information Criterion (AIC), Deviance Information Criterion (DIC), and deviance indices. Results revealed that the model with TFL (Model 4) had smaller values for all indices (see Table 3 for fit indices). Further, Model 4's deviance was significantly lower $(p<.001)$ than the model with AL (Model 3). Taken together, these results suggest Model 4 had slightly better fit. Second, a dominance analysis approach was used to examine predictor importance in MLMs, as suggested by Luo and Azen (2013), to compare the leadership styles. This approach involves the comparison of the explanatory power $\left(R^{2}\right)$, or proportional modeled variance, of the predictors in MLMs. Specifically, $R^{2}$ estimates from Model 3, Model 4, and a model with both predictors, which was labeled Model 5 (see Table 4 for parameter estimates) are compared in this approach. The predictive ability at Level-1 is of interest in this study; therefore, Snijders and Bosker's (1994) approach to calculating $R^{2}$ was used in the analyses (Luo \& Azen, 2013). The dominance analysis revealed that TFL slightly exceeded AL in relative importance when predicting inclusion (see Table 4 for results).

\section{TABLE 4}

\section{DOMINANCE ANALYSIS RESULTS}

\begin{tabular}{|c|c|c|c|c|}
\hline \multirow[b]{2}{*}{ Subset Model } & & \multicolumn{3}{|c|}{ Additional Contribution of } \\
\hline & & $R^{2}$ & $X_{1}$ & $X_{2}$ \\
\hline \multirow[t]{3}{*}{$k=0$} & & & 0.275 & 0.279 \\
\hline & $X_{1}$ & 0.275 & & 0.02 \\
\hline & $X_{2}$ & 0.279 & 0.016 & \\
\hline \multirow[t]{2}{*}{$k=1$} & & & 0.016 & 0.02 \\
\hline & $X_{1} X_{2}$ & 0.295 & & \\
\hline Overall Average & & & 0.1455 & 0.1495 \\
\hline Percentage & & & $49 \%$ & $51 \%$ \\
\hline
\end{tabular}

Note: $X_{1}=\mathrm{AL} ; X_{2}=\mathrm{TFL}$

\section{DISCUSSION}

Inclusion research is still in its early stages and more work is needed to determine how organizations may foster perceptions of inclusive environments and the role of leadership in doing so (e.g., Shore et al., 2018). Although AL and TFL are widely studied styles, they have been shown to be highly related (Banks et al., 2016) and more work is needed to understand important distinctions in their prediction of outcomes. Therefore, this study explored the roles of AL and TFL in the prediction of perceptions of inclusive environments and compared these styles in their prediction.

This study adds to the body of knowledge on inclusion and leadership in several ways. First, we draw from relevant theory (SIP and SLT) in describing why AL and TFL should relate to perceptions of inclusive environments. More specifically, we utilized SIP and SLT to explain how each dimension of AL and TFL may foster perceptions of a relatively recent, yet understudied aspect of inclusion: inclusive environments (Nishii, 2013). Findings add to the empirical body of evidence regarding predictors of inclusive environments by revealing that both AL and TFL are significantly related to perceptions of inclusive environments. In examining these relationships, we use a more recent measure of AL (Neider $\&$ Schriesheim, 2011) and an inclusion measure consistent with a more recent conceptualization of the concept than those measures used in previous work studying similar relationships.

The comparison of the leadership styles as predictors of perceptions of inclusive environments revealed that the model with TFL had slightly better fit than the model with AL, and that TFL demonstrated dominance over AL when comparing explanatory power of the styles. These results contribute to literature comparing these leadership styles by examining them in relation to a relatively 
new and important outcome of perceptions of inclusive environments. Banks et al. (2016) suggest that TFL may be more strongly related to outcomes that reflect an individual level focus and AL may be more strongly related to outcomes that reflect a collective focus. Our results may be interpreted as somewhat contrary to this suggested distinction as inclusive environments could be argued to support more collective interests (e.g., being inclusive to all members as opposed to the formation of group fractions, like in-group and out-groups). However, we hesitate to draw strong conclusions due to (a) our analysis of perceptions of inclusive environments at the individual level and (b) the similarity between the styles, discussed next.

The results of this study also illustrate the strong similarity between AL and TFL styles in terms of their correlation and their prediction of perceptions of inclusive environments. These results support the meta-analytic findings of Banks et al. (2016) that call into question previous evidence that these two styles are in fact distinct. Although Banks et al. (2016) suggested that this overlap may be more prevalent for Walumba et al.'s (2008) Authentic Leadership Questionnaire (ALQ) rather than Neider and Schriesheim's (2011) measure, our results illustrate that this similarity persists with the latter measure as well.

As a practical implication, organizations that wish to foster inclusion in the workplace may choose to develop leaders' AL or TFL styles, with the latter being slightly preferred. Behaviors that are consistent with those laid out within the dimensions of each style may indeed be utilized to create a sense that individuals belong to the work group while also feeling valued for their unique attributes. Ultimately, the associated perceptions of inclusion are expected to result in various positive outcomes for diverse work groups (Nishii, 2013; Shore et al., 2018).

\section{Limitations and Future Directions}

There are several limitations to this study and future directions for research that should be noted. First, based on the cross-sectional nature of the study, causality cannot be determined. However, based on relevant theory, we suspect that the leadership style to perceptions of inclusive environments direction may be more feasible than the reverse. Future research could explore the causal nature of these relationships using longitudinal and experimental designs.

Additionally, the strong correlation between AL and TFL warrants concerns regarding multicollinearity within MLMs that included both predictors (Model 5). Previous research cautions that multicollinearity in MLMs can produce unreliable parameter estimates and may require more power to identify significant effects (Clark, 2013, Shieh \& Fouladi, 2003). Although our sample size provided adequate power, we caution the generalizability and replicability of the parameter estimates of Model 5 . Further, Banks et al. (2016) indicate that, "[c]oncerns about multicollinearity in regression equations suggest that a relative weights analysis is merited" (p. 638). Therefore, although the multicollinearity issue should not be ignored (Tonidandel \& LeBreton, 2011), the results of the analyses may still be informative regarding the relative importance of TFL and AL.

Further, this research only examined the roles of TFL and AL at the composite levels; more work is needed in exploring underlying dimensions of the styles and their associated relationships (Banks et al., 2016). Relatedly, we would like to thank an anonymous reviewer for suggesting a direction for a possible future study that utilizes a person-centered approach to examining leadership. This approach may be particularly useful as individuals may be less likely to categorize their leaders into one style of leadership and may conceptualize them more holistically (e.g., as demonstrating varying levels of each leadership style or dimensions within each leadership style).

Finally, future research may benefit from examining whether these leadership styles impact perceptions of inclusion similarly across subgroups. Although it was not the focus of this study, our results reveal that gender was systematically related to perceptions of inclusive environments, where gender was negatively related to perceptions of inclusive environments, implying females had lower perceptions than males. More research may benefit from exploring the extent to which leadership styles and other factors help foster perceptions of inclusive environments among members of various subgroups. 


\section{REFERENCES}

Ashikali, T., \& Groeneveld, S. (2015). Diversity management in public organizations and its effect on employees' affective commitment: The role of transformational leadership and the inclusiveness of the organizational culture. Review of Public Personnel Administration, 35(2), 146-168.

Avolio, B. J., \& Gardner, W. L. (2005). Authentic leadership development: Getting to the root of positive forms of leadership. The Leadership Quarterly, 16, 315-338.

Avolio, B. J., Gardner, W. L., Walumbwa, F. O., Luthans, F., \& May, D. (2004). Unlocking the mask: A look at the process by which authentic leaders impact follower attitudes and behaviors. The Leadership Quarterly, 15, 801-823.

Bandura, A. (1977). Social learning theory. Englewood Cliffs, NJ: Prentice Hall.

Banks, G. C., McCauley, K. D., Gardner, W. L., \& Guler, C. E. (2016). A meta-analytic review of authentic and transformational leadership: A test for redundancy. The Leadership Quarterly, 27, 634-652.

Bass, B. M., \& Avolio, B. J. (1990). The implications of transactional and transformational leadership for individual, team, and organizational development. Research in Organizational Change and Development, 4, 231-272.

Bass, B. M., Avolio, B. J., Jung, D. I., \& Berson, Y. (2003). Predicting unit performance by assessing transformational and transactional leadership. Journal of Applied Psychology, 88, 207-218.

Boekhorst, J. A. (2015). The role of authentic leadership in fostering workplace inclusion: A social information processing perspective. Human Resource Management, 54(2), 241-264.

Brimhall, K. C., Mor Barak, M. E., Hurlburt, M., McArdle, J. J., Palinkas, L., \& Henwood, B. (2017). Increasing workplace inclusion: The promise of leader-member exchange. Human Service Organizations: Management, Leadership \& Governance, 41(3), 222-239.

Clark, P. C. (2013). The effects of multicollinearity in multilevel models (Doctoral dissertation). Retrieved from http://corescholar.libraries.wright.edu/etd_all.

Cottrill, K., Lopez, P. D., \& Hoffman, C. C. (2014). How authentic leadership and inclusion benefit organizations. Equalty, Diversity, and Inclusion: An International Journal, 33(30), 275-292.

Ferdman, B. M., \& Deane, B. R. (2014). Diversity at work: The practice of inclusion. San Francisco, CA: Jossey-Bass.

Gardner, W., Cogliser, C., Davis, K., \& Dickens, M. (2011). Authentic leadership: A review of the literature and research agenda. The Leadership Quarterly, 22, 1120-1145.

Gotsis, G., \& Grimani, K. (2016). The role of servant leadership in fostering inclusive organizations. Journal of Management Development, 35(8), 985-1010.

Hannah, S. T., Walumbwa, F. O., \& Fry, L. W. (2011). Leadership in action teams: Team leader and members' authenticity, authenticity strength, and team outcomes. Personnel Psychology, 64, 771802.

Ilies, R., Morgeson, F. P., \& Nahrgang, J. D. (2005). Authentic leadership and eudaemonic well-being: Understanding leader-follower outcomes. The Leadership Quarterly, 16, 373-394.

Judge, T. A., \& Piccolo, R. F. (2004). Transformational and transactional leadership: A meta-analytic test of their relative validity. Journal of Applied Psychology, 89, 755-768.

Leroy, H., Anseel, F., Gardner, W., \& Sels, L. (2015). Authentic leadership, authentic followership, basic need satisfaction, and work role performance: A cross-level study. Journal of Management, 41, 1677-1697.

Liao, H., \& Chuang, A. (2007). Transforming service employees and climate: A multilevel multi-source examination of transformational leadership in building long-term service relationships. Journal of Applied Psychology, 92, 1006-1019.

Luo, W., \& Azen, R. (2013). Determining predictor importance in hierarchical linear models using dominance analysis. Journal of Educational and Behavioral Statistics, 38, 3-31. 
Luthans, F., \& Avolio, B. (2003). Authentic leadership development. In Cameron, K. S., Dutton, J. E., \& Quinn, R. E. (Ed.), Positive organizational scholarship: Foundations of a new discipline (pp.

241-258). San Francisco, CA: Barrett-Koehler Publishers, Inc.

Merlini, K. P., Bupp, C. P., Garza, M. M., \& Merlini, P. G. (2018, April). Inclusion and intent to leave: The mediating role of burnout. Poster session presented at the 33rd annual conference for the Society for Industrial and Organizational Psychology, Chicago, IL.

Mhatre, K. H., \& Riggio, R. E. (2014). Charismatic and transformational leadership: Past, present, and future. The Oxford Handbook of Leadership and Organizations, 221-240.

Mor Barak, M. E., \& Cherin, D. A. (1998). A tool to expand organizational understanding of workforce diversity. Administration in Social Work, 22, 47-64.

Neider, L. L., \& Schriesheim, C. A. (2011). The authentic leadership inventory (ALI): Development and empirical tests. The Leadership Quarterly, 22, 1146-1164.

Nishii, L. H. (2013). The benefits of climate for inclusion for gender-diverse groups. Academy of Management Journal, 56(6), 1754-1774.

Ostroff, C., Kinicki, A. J., \& Tamkins, M. M. (2003). Organizational culture and climate. In W. C. Borman, D. R. Ilgen, \& R. J. Klimoski (Eds.), Handbook of psychology: Industrial and organizational psychology, Vol. 12, pp. 565-593). Hoboken, NJ: John Wiley \& Sons Inc.

Peugh, J. L. (2010). A practical guide to multilevel modeling. Journal of School Psychology, 48, 85-112.

Randel, A. E., Galvin, B. M., Shore, L. M., Ehrhart, K. H., Chung, B. G., Dean, M. A., \& Kedharnath, U. (2018). Inclusive leadership: Realizing positive outcomes through belongingness and being valued for uniqueness. Human Resource Management Review, 28(2), 190-203.

Rodriguez, R. A., Green, M. T., Sun, Y., \& Baggerly-Hinojosa, B. (2017). Authentic leadership and transformational leadership: An incremental approach. Journal of Leadership Studies, 11, 20-35.

Salancik, G. R., \& Pfeffer, J. (1978). A social information processing approach to job attitudes and task design. Administrative Science Quarterly, 23, 224-253.

Schneider, B., Ehrnhart, M. G., \& Macey, W. H. (2013). Organizational climate and culture. Annual review of Psychology, 64, 361-388.

Shieh, Y-Y. \& Fouladi, R. T. (2003). The effect of multicollinearity on multilevel modeling parameter estimates and standard errors. Educational and Psychological Measurement, 63, 951-985.

Shore, L. M., Cleveland, J. N., \& Sanchez, D. (2018). Inclusive workplaces: A review and model. Human Resource Management Review, 28, 176-189.

Shore, L. M., Randel, A. E., Chung, B. G., Dean, M. A., Ehrhart, K. H., \& Singh, G. (2011). Inclusion and diversity in work groups: A review and model for future research. Journal of Management, $37,1262-1289$.

Snijders, T., \& Bosker, R. J. (1994). Modeled variance in two-level models. Sociological Methods \& Research, 22, 342-363.

Sosik, J. J., \& Jung, D. (2010). Full range leadership development: Pathways for people, profit, and planet. New York, NY: Routledge.

Taylor, S. E. (1989). Positive illusions: Creative self-deception and the healthy mind. New York: Basic Books.

Thomas, J. G., \& Griffin, R. W. (1989). The power of social information in the workplace. Organizational Dynamics, 18, 63-75.

Tonidandel S., \& LeBreton J. M. (2011). Relative importance analysis: A useful supplement to regression analysis. Journal of Business and Psychology, 26, 1-9.

Walumbwa, F. O., Avolio, B. J., Gardner, W. L., Wernsing, W.S., \& Peterson, S. J. (2008). Authentic leadership: Development and analysis of a multidimensional theory-based measure. Journal of Management, 34, 89-126.

Walumbwa, F., Luthans, F., Avey, J., \& Oke, A. (2011). Authentically leading groups: The mediating role of collective psychological capital and trust. Journal of Organizational Behavior, 32, 4-24.

Xirasagar, S., Samuels, M. E., \& Stoskopf, C. H. (2005). Physician leadership styles and effectiveness: An empirical study. Medical Care Research and Review, 62, 720-740. 


\section{APPENDIX}

TABLE 1

SUBSAMPLE PARTICIPANT DEMOGRAPHICS

\begin{tabular}{|c|c|c|c|}
\hline \multicolumn{2}{|c|}{ Demographic } & \multirow[t]{2}{*}{ Number } & \multirow[t]{2}{*}{ Percentage $(\%)$} \\
\hline Gender & & & \\
\hline & Male & 2921 & $76 \%$ \\
\hline & Female & 913 & $24 \%$ \\
\hline \multicolumn{4}{|l|}{ Race } \\
\hline & White (Caucasian) & 2311 & $60 \%$ \\
\hline & African American & 445 & $12 \%$ \\
\hline & Asian & 170 & $4 \%$ \\
\hline & American Indian or Alaskan Native & 44 & $1 \%$ \\
\hline & Native Hawaiian or Other Pacific Islander & 49 & $1 \%$ \\
\hline & Selected multiple races & 177 & $5 \%$ \\
\hline & Declined to Respond & 638 & $17 \%$ \\
\hline \multicolumn{4}{|c|}{ Branch of Service } \\
\hline & Army & 1262 & $44 \%$ \\
\hline & Navy & 1010 & $35 \%$ \\
\hline & Marine Corps & 375 & $13 \%$ \\
\hline & Air Force & 187 & $7 \%$ \\
\hline & Coast Guard & 25 & $1 \%$ \\
\hline
\end{tabular}




\begin{tabular}{|c|c|c|c|}
\hline \multicolumn{4}{|l|}{ Rank } \\
\hline & Junior Enlisted & 639 & $17 \%$ \\
\hline & Non-Commissioned Officers & 1528 & $40 \%$ \\
\hline & Senior Non-Commissioned Officers & 290 & $8 \%$ \\
\hline & Junior Officers & 241 & $6 \%$ \\
\hline & Senior Officers & 161 & $4 \%$ \\
\hline & Junior Civilian & 499 & $13 \%$ \\
\hline & Senior Civilian & 359 & $9 \%$ \\
\hline & Wage Grade & 38 & $1 \%$ \\
\hline & Non Appropriated Funds & 28 & $1 \%$ \\
\hline & Other & 51 & $1 \%$ \\
\hline \multicolumn{4}{|c|}{ Military/Civilian } \\
\hline & Military & 2859 & $76 \%$ \\
\hline & Civilian & 924 & $24 \%$ \\
\hline
\end{tabular}

Note: Percentage values are rounded to the nearest whole number. 